\section{Intramural Rupture of the Oesophagus: A Case Report of a Unique Endoscopic Appearance}

Between transmural rupture of the oesophagus (Boerhaave syndrome) (1) and mucosal oesophageal tears (Mallory-Weiss syndrome) (2), there lies a less well described syndrome known as intramural rupture of the oesophagus $(3,4)$.

A 64-year-old woman presented in July 1994 with haematemesis. The blood was bright red, small in quantity, and at the end of a vomiting episode, some chest discomfort started during the vomiting and remained. She was mildly distressed, with a pulse of 108 and a temperature of $37.5 \mathrm{C}$. There was no surgical emphysema, and the chest examination was unremarkable. Apart from a white blood cell count of $14.3 \times 1000 / \mathrm{mm}^{3}$, her laboratory tests, her electrocardiogram and a chest radiograph were all normal. Subsequently, her temperature rose to $38^{\circ} \mathrm{C}$ and her white blood cell count reached 22.9 , with persistent chest discomfort and dysphagia. Two days later, she underwent an upper gastrointestinal endoscopy. This revealed a longitudinal mucosal tear extending along the middle and lower oesophagus on the left side, and stopping short of the cardia. The base of the tear showed paradoxical movement with respiration (Figure 1). At the lower end, there was a small hole (Figure 2). There was some bubbling with respiratory movements from this hole, which it was thought might represent a complete tear. She was started on intravenous antibiotics, $\mathrm{H}_{2}$ antagonists, and kept strictly on a nil by mouth regime. Total parenteral nutrition was started. A water-soluble contrast study of the oesophagus was obtained. This showed a tiny, contained leakage from the lower oesophagus, coinciding with the endoscopic appearance. Over the following days, her chest discomfort markedly improved, and her temperature returned to normal. On day ten, the patient underwent a further endoscopy, which showed satisfactory healing of the tear (Figure 3). She was allowed to eat and drink, and discharged home. She has remained well since then.

Endoscopy was useful in this case in order to exclude other causes of haematemesis, to plan treatment, and for follow-up. With a careful technique, the theroretical risk of complete perforation is minimal. The patient was treated conservatively, in the absence of any signs of uncontrolled sepsis.

\section{H. Souka}

Surgical Dept., St. Helier Hospital, Carshalton, Surrey, England

\section{References}

1. Pate JW, Walker WA, Cole FH, Owen EW, Johnson WH. Spontaneous rupture of the esophagus: a 30-year experience. Ann Thorac Surg 1989; 47:689-92.

2. Folan RD, Smith RE. Head JM. Esophageal hematoma and tear requiring emergency surgical intervention: a case report and literature review. Dig Dis Sci 1992; 37: 1918-21.

3. Steadman C, Kerlin P, Crimmins F, Bell J, Robinson D, Dorrington L, et al. Spontaneous intramural rupture of the Oesophagus. Gut 1990:31: 845-9.

4. Girdwood AH, Silber W, Kottler RE, Alexander MG, Marks IN. Intramural rupture of the oesophagus. S Afr Med J 1982; 60: $695-8$.

5. Kerr WF. Spontaneous intramural rupture and intramural haematoma of the oesophagus. Thorax 1980; 35: 890-7.
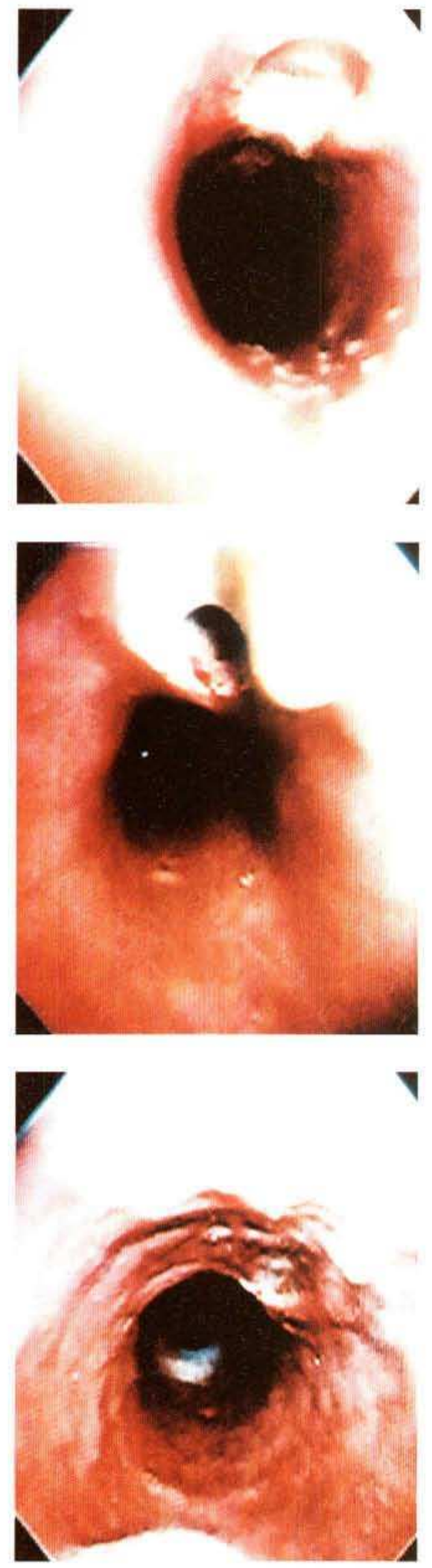

F

Figure 3: Satisfactory healing of the tear on subsequent endoscopy.

A smal hole is seen at the extreme lower end of the longitudinal oesophageal tear.

Corresponding Author

H. Souka, M. D., Surgical Dept., St. Helier Hospital,

Wrythe Lane, Carshalton, Surrey SM51 AA.

United Kingdom 